\title{
Contraceptive services for adolescents
}

\author{
Lindsay Edouard, MSc, FFPHM, FRCOG, MFFP \\ Overseas Adviser, Journal of Family Planning and Reproductive Health Care
}

In 1939, Dr Margaret Jackson fitted her first intra-uterine contraceptive device, at the request of a farmer, in his daughter who had already had two births from 'tumbles in the hay' with casual partners. ${ }^{1}$ Besides various myths regarding the value of contraceptive methods for adolescents, certain organisational issues continued to hamper service provision until recently.

It was not until the late sixties that unmarried individuals officially obtained access to contraceptive services in Britain. ${ }^{2}$ With an unsuccessful grant application to the city council, the founding of an alternative centre providing contraception to young people had necessitated a bank loan: its opening in 1966 'was a nine-day wonder in Sheffield and was besieged by the press, denounced by the clergy and welcomed by the clients'. ${ }^{3}$ However, by 1973 the same council was paying for those services; that commitment was taken over by the National Health Service in 1975 when the centre became part of the establishment, albeit in funding only, and its appearance was kept deliberately 'as seedylooking and non-establishment as possible'. ${ }^{3}$

Family planning doctors appreciated the legal implications of their professional advice ${ }^{4}$ regarding adolescent sexuality and disapproved of a 'return to the ostrich-like position of the past when we buried our heads in the sand and refused to see the very young'; this led to initiatives for the lowering of the age of consent. ${ }^{5}$ There had already been state reluctance to interfere in the bedrooms of the nation, except in exceptional circumstances involving violence or minors. Besides not being enforceable, the law making a criminal offence of sexual relations with girls younger than 16 adversely affected their utilisation of health services through delaying clinic attendance until the sixteenth birthday. ${ }^{6}$
Service providers should acknowledge the importance of adolescent sexuality, especially with the earlier age at first intercourse, through open attitudes and responsiveness to adolescent needs, whether overt or not. Besides, contraceptive services should be provided in the broader context of reproductive health and linked to sexuality education, including relationships, self-esteem, decisionmaking and assertiveness skills.

The evolving psychosocial context of adolescent sexuality was already being considered for the dissemination of information and the provision of contraception $^{7}$ in 1976 , but the legal situation was not clarified until 1985 with the ruling of the House of Lords which allowed the prescription of contraceptives to competent minors without parental consent. ${ }^{8}$ Service provision to adolescents has been further facilitated through international initiatives, such as the Convention on the Rights of the Child ${ }^{9}$ which is applicable up to the eighteenth birthday, and medical eligibility criteria for contraceptive methods ${ }^{10}$ from the World Health Organization.

United Nations. Contributions from the United Nations agencies, programme, funds, an bodies on their follow-up to the World Summit for Children. Preparatory Committee for the Special Session of the General Assembly on Children. A/AC.256/CRP.8. New York: United Nations, 2001: 15, 19, 77, 171, 190, 246, 259, 269 .

World Health Organization. Improving access to quality care in family planning - medical ligibility criteria for contraceptive use. Second edition. WHO/RHR/00.02. Geneva: Worl Health Organization, 2000: 12 .
} 